\title{
Identifying Indicators of the Construct for Motivation for Weight Loss: Designing a Questionnaire
}

\author{
Fikirte Lakew ABEBE* (PhD candidate), (Corresponding Author) \\ Department of Psychology, Debreberhan University, Ethiopia \\ Co-Author: Menna Olango AGAGO** (PhD), Associate Professor \\ College of Education, Hawassa University, Ethiopia
}

\begin{abstract}
*This study is based on the first author's PhD thesis entitled "Development and Validation of Instrument to Assess Motivation for Weight Loss" and was written under the supervision of the other author.

** Associ. Prof. Dr. Manna Olango AGAGO, College of Education, Hawassa University, Hawassa, Ethiopia, mannaolangoargago@gmail.com
\end{abstract}

\begin{abstract}
The prevalence of overweight and obesity is rising rapidly throughout both the developed and the developing world, and it is creating social, economic and health burden on society particularly in urban areas (Popkin, 2006 in Tesfalem, 2013). As a part of designing a questionnaire, the current research aims to identify the indicators of the latent construct motivation for weight loss. To achieve this, the paper raised the following two specific research questions: What are the indicators of the motivation for participation for weight loss program? And where do the indicators fit in the factors of social determination theory (SDT)? To gain a rich understanding of the motivation for the participation in weight loss program, semi-structured focus group discussions (FGD) were conducted with purposely recruited samples of two groups: overweight people and their interventionists. Based on the themes identified from the FGD the indicators were identified. Besides, from the consultations gained from the review of related literature the indicators were placed in SDT.
\end{abstract}

Keywords: Overweight, Weight loss, Motivation, Self-Determination Theory (SDT)

DOI: $10.7176 / \mathrm{JEP} / 12-28-03$

Publication date:October $31^{\text {st }} 2021$

\section{Introduction}

The global prevalence of the overweight and obesity has been significantly increasing over the past four decades. Nearly one-third of the global population is overweight or obese, that is, more than 2.1 billion (Yatsuya, Hilawe, Ota, Wang, Chang, Zhang, Uemura, Osako, Ozaki, and Aoyama, 2014). The combined prevalence of overweight and obesity has increased by $27.5 \%$ for adults and $47.1 \%$ for children between 1980 and 2013 (Solomon, Solomon, and Kedir, 2016). The prevalence of obesity is rising rapidly throughout both the developed and the developing world, and it is creating social, economic and health burden on society. If current trends contrive, it is estimated that by 2030 almost half of the world's adult population will be overweight or obese (Kelly, Yang, Chen, Reynolds, and $\mathrm{He}, 2008)$.

Such a scenario would have devastating consequences for the global burden of non-communicable diseases, with increasing body mass index (BMI) associated with an elevated risk of developing a chronic disease such as cardio vascular disease, diabetes, respiratory disease, and certain cancers (Tennant, 2014; Desalegn, 2016; Dereje, Gudina, and Tefera, 2018; Ogunbode, Ladipo, Ajayi and Fatiregun, 2011).

There is a growing pattern of overweight and obesity in Ethiopia especially in urban areas. WHO estimated in 2008 in Ethiopia, the prevalence of death due to overweight and obesity were $7.4 \%$ and $1.1 \%$, respectively (Mulugeta, Mekitie, Alemayehu, Shikur, Zewdu, Mukerem, and Gebresilasea, 2015). As reported in Ethiopian Public Health Association (2012) and by Dagim and Minyahil (2017), there is a high prevalence of overweight among adults in Addis Ababa. Close to 30\% of dwellers in Addis Ababa were overweight or obesity. This situation calls for well-planned weight management procedure.

The management of obesity may emerge from two treatment options: medication and life style modification. Medication represents a treatment obese people receive from physicians. This treatment focuses on prescriptions of drugs and/or excision of excess fats through surgery. The former treatment of obesity is formulated to reduce energy intake, increase energy output or decrease the absorption of nutrients (Ogunbode, et al, 2011). In general, the drugs are administered (prescribed) to decrease absorptions of nutrients, to suppress appetite of the obese person, or to decrease fat absorption. However, these drugs should be administered with caution and within a limited length of time. With this unsafe condition, they are found to be ineffective for treatment of obesity (Ogunbode, et al, 2011). The later, excision of fats through surgery can be done from various parts of the body.

The second treatment option for obesity is lifestyle modification which comprises dietary restriction and exercise. Dietary selection includes the quantity and quality of scheduled food intake. Exercise is an integral part 
of lifestyle modification. According to Ogunbode et al (2011), regular exercise reduces the risk of coronary heart disease, diabetes mellitus, obesity, colon cancer and osteoporosis. It also helps to minimize anxiety and intensity of depression. Preventing obesity may reduce both the prevalence and severity of several of these illnesses, and reduce medical at individual and national level. Many findings have been reported from researches that have examined exercise alone, dietary restriction alone, or combination of the two to determine mechanisms for weight loss (Cox, 2017).

It is widely accepted that the combination of a healthy diet and regular exercise has been shown to improve weight loss (Silve et al., 2011 in Tennant, 2014). Acknowledging the contribution of healthy diet and regular exercise for weight loss, Resnicow et al., (2008), in Ceccarini (2015), contend that the mere knowledge of dietary prescriptions and of physical activity programs is not enough to lose bodyweight. Ceccarini mentioned Castelmeoro et al., (2010) who reported that the weight losers went back to their original weight in three to five years of their last recorded weight loss. These researchers have called physiological mechanism such as the role of motivation into the attention of researchers to maintain weight loss effort. NHLRI (2015), in Andres, Saldana and Beeken, (2015), took a supporting position that weight loss management is better approached with the gold standard which is a combination of behavioral treatment with diet and physical activity. The current research of identifying the indicators for a questionnaire to assess motivation for weight loss was conducted with this existing status of the threatening prevalence of overweight in urban areas.

\section{Study Setting and Participants}

The target discussants were composed of two groups of people: interventionists and overweight people. The former included physical fitness practitioners, nutritionists, and medical staff. The latter were overweight people who had body mass index (BMI) between 26 and 37 inclusive and were aged between 22-34 inclusive. Besides, for accessibility of the discussants and for exclusion criteria (overweight people who were medically prohibited from involving in weight loss programs were excluded), fitness centers, clinics, and hospitals were research settings. The target population was situated in Addis Ababa for a reason that, as reported in Ethiopian Public Health Association (2012) and by Dagim and Minyahil (2017), overweight was high in Addis Ababa. It was close to $30 \%$ of its dwellers. The amount of the prevalence is likely to increase since then.

\section{Types of Data Collected}

The researchers believed that FGD could generate an in-depth understanding of the behaviors overweight people are required to get motivated. Semi-structured FGDs were used based on an outline structure of some key questions. This mode was intended to get discussants express their ideas in their own terms. The questions were formulated following the advice of the prominent scholar named Patton (2015) in the area of qualitative questions formation. Patton suggested six kinds of questions: experience questions, opinion and value questions, feeling questions, knowledge questions, sensory questions, and background/demographic questions. Advice from Patton (2015), consultation from the review of related literature, and the nature of the specific questions of the current research were considered to prepare the questions for the FGDs. Twelve questions were prepared in advance for the two groups of discussants in the FGDs.

We asked three researchers that used qualitative research methodology in their work to comment on the nature of the items. Besides, the principal researcher conducted a pilot test with one overweight person and one interventionist to see if the items were comprehensible to the discussants. These two procedures led the current researchers to remove and modify the items into nine items.

The questions were given to the discussants in written form because they would get time to activate the information they had in their mind. The researcher believed that reading would facilitate the processing of the questions in their mind. This might help them to respond to the questions easily and very well. The questions were given to them one-by-one in order to reduce the interference of the processing of the other questions on their processing of the question under discussion.

The moderator was jotting down the main points while the group members were talking about the discussion questions. She, then, reflected the points back to the discussants at the end of the discussion. To gain discussants' confirmation, she invited the members to add what they thought missed and to omit what they thought did not represent their ideas.

\section{Analysis}

The current researchers have taken the inaugural type of instrumentation. The decision to develop a questionnaire from a scratch puts two approaches for the researcher to select and follow in the course of developing a questionnaire. The approaches are research-before-theory and theory-before-research. The current researchers adopted the former which can be presented by the following figure (Berg, 2001:18). 


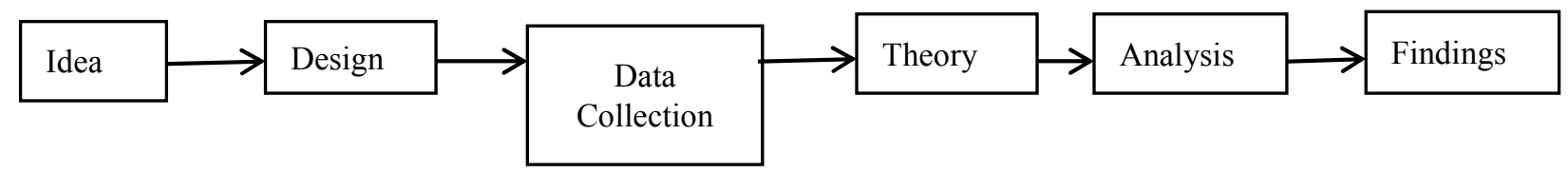

The first step in data analysis was to explore the data. This provided the opportunity for the researchers to obtain a general sense of the data, and consider whether the researchers needed more data or not. The researchers read the transcribed data several times. This was immersing themselves in the details, trying to get a sense of the data as a whole before breaking it into parts (Agar, 1980 in Creswell, 2012). This experience gave the current researchers crude criteria to identify important points among the bulk of the transcribed data.

In an attempt to provide more useful context, phrases, a sentence or group of sentences were used as levels or units of analysis. Besides, coding frame was prepared to make the concepts specific for coding. Applying and consistently following the frame allowed the researchers to maintain the validity of the data (Wilkinson and Birmingham, 2003) on generating the indicators for the construct of motivation for weight loss.

The data from FGDs were analyzed with the help of another rater. The principal researcher and the rater compared the consistency of their rating. The researchers employed Miles and Huberman's (1994, p. 64) formula to calculate the raters' reliability. According to them, reliability equals the number of rater agreements divided by that number of agreements plus the number of disagreements.

Reliability $=\quad \frac{\text { Agreement }}{\text { Agreement }+ \text { Disagreement }}$

On 17 of the indicators the raters agreed, but on 4 they did not. According to the reliability formula, the reliability was 17 divided by 21 plus 4 , or 17 divided by 21 for a reliability of 0.81 .

Reliability $=\frac{17=0.81}{17+4}$

The two raters discussed the four disagreements and finally agreed on three of them resulting in a formula of 20 agreements and 1 disagreement for a final reliability of 0.96 , which is a high level of inter-rater reliability.

\section{Results and Discussion}

The findings of the research will be presented in the following two consecutive sub-sections which stand for the two basic research questions this qualitative research aimed to address.

\section{Indicators of Motivation for Weight Loss}

We will raise each of the discussion questions and identify the indicators of the construct of motivation for weight loss with the purpose of addressing the first research question.

1. What are the characteristics of the participants?

For the qualitative study, one of the two FGDs had to be composed of overweight people. This question was aimed at eliciting information about the illegibility of the people to participate in FGD. The question mainly targeted to recruit eligible participants who were overweight based on the measure of body mass index (BMI). Therefore, the moderator asked them about their height in meters (or centimeters) and weight in kilos. This question was forwarded for the clients in order to check whether they were overweight or not. They had body mass indices between 26 and 37.

Table 1: Distribution of discussants by sex

\begin{tabular}{|l|l|l|}
\hline Sex & Overweight & Interventionists \\
\hline F & 3 & 1 \\
\hline M & 1 & 3 \\
\hline
\end{tabular}

2. What are your reasons to come to the physical fitness centers?

This question was forwarded to get their motives behind their decision to participate in a weight loss program. This question was made to receive conceptually relevant responses which contributed to the content validity of the 
items to be developed later in the stages of developing items for assessing the motivation to participate in a weight loss program.

The discussants forwarded a variety of responses which can be represented by the following headings: habits, goals, health, pleasure, people, and amotivation.

\section{Habits}

The following extracts are instances that show the discussants' habits in connection with their experience in weight loss.

I did it er...er ... for a long... a long time and it...it is almost part of mine...er...my life

For me, I ...did it for more than er...er...er... yes for more than 12 years. When I began, er... it was to...to..to improve my health status. I saw... I achieved this. I continued involving in the weight loss program. It is almost...er almost part of of my life.... I don't know how life looks like without physical exercise and diet selection.

It is...almost a habit for me and I don't...er...er...feel good if I am not doing ....er I am not doing physical exercise

I like...I enjoy...I mean I must do physical exercises periodically.

Yea...for some it is almost a habit. Their body accustomed to the rules and regulations of the weight loss program. They feel ashamed of themselves. .... They feel guilty when they cancelled schedule.

Sand, Emaus, and Lian (2017) have found out that cultivating the appropriate life style habits has increased the participants' confidence in their ability to manage their weight. Therefore, having and sustaining the appropriate habit was considered one of the indicators of motivation for weight loss.

\section{Achieving Goal}

The following episode from the discussants is an example to show their reason to participating in a weight loss program.

My first goal is ...well...no other only the right BMI.

This excerpt could be taken as one of the indicators for the construct of the motivation for weight loss. Aiming for a BMI of $25 \mathrm{~kg} / \mathrm{m}^{2}$ for their clients is one of the responsibilities of the interventionists (Ogunbode, Ladipo, Ajayi, and Fatiregun, 2011).

\section{Improving Health}

The discussants shared their reasons to involve in weight loss program. Among the many reasons the discussants mentioned, improving their health condition was salient. Their original words reflect this.

For me, I ...did it for more than er...er...er... yes for more than 12 years. When I began, er... it was to...to..to improve my health status. I saw... I achieved this. I continued involving in the weight loss program. It is almost...er almost part of of my life....I don't know how life looks like without physical exercise and diet selection.

Sand, Emaus, and Lian (2017) also found that fitness and the pursuit of looking healthy was the recurrent topic among the overweight people. Their commitment to be fit and look healthy could be taken as indicator for motivation to lose weight.

A further probing on "What will the success bring you?" for deeper understanding brought the following responses which are relevant to the research agenda.

\section{Pleasure of Weight Loss}

Some discussants reflected their delight in participating in a weight loss program. ...for the joy I...er... feel when I engage to...to... myself in the weight loss procedure

Er...for me...the joy of involving in the weight loss ... In fact, er...er... the weight loss is a secondary reason - my primary reason is er ...er ...er... the pleasure I get ...get from coming here.

...my friend I ...my friend takes the responsibility for his overweight... he blames nothing... he...yes enjoys the program

In connection with these excerpts, Sand, Emaus, and Lian (2017) reported that the participants who were exercising on regular basis highlighted the pleasure of the activities. That is, they performed the activities for the joy they get 
from the physical exercises. The participants in Sand, Emaus, and Lian's (2017) research described the physical exercise as genuinely joyful pursuits.

\section{People}

The discussants said that their effort to lose weight could stem from their relationship with family (and friends) and other people around them. The following episodes substantiate this claim.

I don't eat unhealthy food ... because er...er... I don't ... want my family and friends to be unhappy

I want others to admire me (laughing)

...to have a good relationship with others

To have a good relationship with my friends who are working in the entertainment industry.

Like Selam said, people will admire me, I hope,...because it is a big success er...er...imagine if

I throw this (touching and squeezing her belly) way.

Similar to the position of the discussants, Sand, Emaus, and Lian (2017) hold that parents, family members, and people around the overweight person can be important influencers in the practice of losing weight. These people are supportive motivators regarding losing weight. This is more important especially when the patient, the overweight person, is extrinsically motivated.

\section{On Amotivation}

The discussants forwarded an interesting point about the motivation of some people who participated in weight loss programs. The following excerpts from the words of the overweight people and the interventionists are instances to reflect this point.

I know a young boy who goes to a fitness center for no reason. So he sometimes comes sometimes does not....Teddy, added in a humorous tone there are many especially the teenagers. (others laugh)

The interventionists also shared this. In this connection the following excerpt could be taken as evidence. In fact, we have clients who come... I mean ...er...er appear to the center, but er...they don't follow the schedules. This er....er... we tell them again and again...this won't bring the desired result. We don't... encourage...such behaviors.

These episodes clarify that there were individuals who participated in a weight loss intervention for no reason. These people are amotivated.

3. What are the responsibilities of an overweighed person to be successful in losing weight?

This question was designed to come up with the focus and commitment areas of the overweighed people and their interventionists. Their responsibilities were believed to come out from their areas of focus. The responses showed the things they were required to perform as overweight people and as interventionists. The researchers believed that the responses would contribute to the content validity of the ideas generated to get the indicators of the construct of motivation for weight loss.

Concerning the responsibility of the over-weights to lose weight, the discussants forwarded their ideas among which the following are included.

My responsibility ...mmm ...following...following the instructions of ...Er...Er ... my ...my coach Er...Er... for example...doing physical exercises as he prescribed

I agree with what she said. Besides, I must eat the food items selected to help me manage my body weight.

Following the advices of my coach with commitment. Er...er...this means doing physical exercises regularly and following the dietary schedules strictly.

Time...er...er...I me...mean doing the physical exercises not only regularly but also not plus or minus of the length of time scheduled for the day. Er...er...sometimes they type of...of sports matter.

NHLBI Obesity Education Initiative (2000), Crane, Fate, Finkelstein, Linnon (2012) and Sand, Emaus, and Lian (2017) underlined the relevance of frequent contact with interventionists during modifying life style in general and during diet adjustment and selecting the types and intensity of physical exercise to do. 
4. What do the interventionists do before starting the intervention?

This question was tailored to collect information on the values the interventionists prioritize for their clients to be successful in losing weight. The priority areas represented the issues that require motivation of the clients. Identifying these areas was believed to contribute to the content validity of the indicators of the construct of motivation for weight loss.

The discussions of both the overweight and the interventionists brought the following summary of points to the attention of the researcher. They were:

- Measuring BMI

- Interviewing the client on his/her health status

- Reasons/goals for coming to the center

- About dietary restrictions and selections

- Scheduled physical exercises

- Psychological readiness to be successful such as mental readiness and capability beliefs

- Acquainting the clients with the rules and regulations of the fitness center such as being punctual when they come in and when they finish, being supportive to other people involving in the center, and using materials and machines properly.

Various scholars (Apovian, 2016; Gurevich-Panigrahi, Panigrahi, Wiechec, Los, 2009; Ogunbode, Ladipo, Ajayi, and Fatiregun, 2011; Sand, Emaus, and Lian, 2017; and others) agree with interventionists that the going through the practice of physical exercises and diet restrictions could have a further irreversible damaging result on the participants if proper care has not been in place. For example, the food selection and restriction could be connected with their blood type on the one hand their health status on the other. If a client has a problem related to his/her backbone much care is required in choosing the types of sports to do.

Once we know that we are fit to enroll and decide to participate, the centers provide additional support for us to start and engage in the program. Some are:

- Written schedule of dietary selection

- Oral advice

- Videos of successful clients

- Videos of motivational speeches (or speakers)

Ogunbode, Ladipo, Ajayi, and Fatiregun (2011) underlined that it is essential to maintain the overweight person's motivation throughout the course of the intervention. Ongoing follow up of the interventionist has been shown to help sustain weight loss. These supportive mechanisms could have significant impact, they believe, in taking the participants to achieving the desired target.

5. What are the advices you have received from your coach?

This question was tailored with almost the same purpose with question number 4. It was a further probing and resulted in the following summary of responses: to gather information about what their interventionists want them to do or to improve to be successful in their weight loss effort. Their responses are categorized into three related groups: modifying dietary and physical exercises, appropriate amount of food intakes and exercise doings, and being personally motivated.

\section{Modifying Dietary and Physical Exercises}

The interventionists advised the overweight people on the importance of modifying the food items they eat and the kind of physical exercises they engage themselves. To substantiate this, the following episode is worth quoting. On dietary selection and on doing physical exercises

NHLBI Obesity Education Initiative (2000) put it in a straight language saying, "Dietary therapy includes instructions of modifying diets" (p. 2) to lose weight. Apovian (2016) stated that consuming fruits and vegetables were protective against overweight. Those who consumed these food items were unlikely to develop overweight. Therefore, this piece of advice was relevant for the overweight people to lose weight.

\section{Appropriate amount of food items and physical exercises}

In addition to modifying dietary selection and doing physical exercise, the discussants also reflected their ideas on the amount of food they should eat and of physical exercise they should do to be successful in their target to reduce their weight.

The food items I am expected to eat with measured amount

On avoiding eating for my emotion. I shouldn't eat food because I like it but because my body needs it. 
Concerning physical exercises Er...Er... I said earlier my coach told me to do physical exercise with appropriate amount. Both too much and too little are ineffective.

Apovian (2016) recommended that overweight people engage in different types of physical activities with appropriate intensity as recommended by the interventionists.

\section{Personal motivation}

According to the discussants, the interventionists advised on the relevance of being motivated to the process of the intervention to achieve their target of losing weight. The next episode is an instance in substantiating their responses.

Having motivation to the intervention is important

Ogunbode, Ladipo, Ajayi, and Fatiregun (2011) stated that personal motivation of the overweight can dramatically influence the intervention procedure. Therefore, the advice is vitally important for the success of losing weight.

6. Is there anything you are not comfortable with?

This question was intended to elicit (generate) data which might reveal the depth of their motivation to push forward through the challenges until they achieve their set target in the weight loss program. Following are three excerpts taken from the responses of the discussants.

Some of the food stuffs I am restricted from were pleasure inducing for me. And it is still a challenge to avoid them from my dining table. The most challenging is when I see them on the table prepared to celebrate wedding ceremony or whatever. It is really challenging.

The intensity of the exercise was uncomfortable for me till my body accustomed to it. Sometimes

I feel quitting, but I, with the support of my coach, go forward.

On their side, the interventionists showed a similar position to the overweight discussants. The following episode reflects this sameness.

The procedure and the intensity of the physical exercise are on our hand. We can see their level

of achievement. On the contrary, we can't be sure about their following the dietary schedule.

Through interview, some are not serious about the restrictions and selections.

It is expected for the overweight people to face such challenges while participating in the weight loss intervention. But the interventionist is responsible to professionally handle this. If exercise levels are unsatisfactory, the interventionist should motivate the overweight to increase physical activity.

The discomforts possibly stemmed from food restrictions and selections and the intensity of physical exercises and the behavior of the client.

7. What do you expect from the intervention?

This question was formulated to find out what they expected to see at the end of the intervention. This came up with the ideas they held as measures of their success. In other words, the responses of the discussants would be relevant in exposing their final goals. These goals might reflect the type of motivation they had. By extension, the responses would contribute to the content validity of the indicators of motivation for weight loss.

The expectations of the discussants in the overweight group are demonstrated through the following words.

I expect to be in good shape

Me...er...er...being attractive

I ...er...mainly to measure the right BMI.

I enjoy it so I want to stay in the program

I want to have flexible body

I want ... yes... to be healthy

Sand, Emaus, and Lian (2017) reported that participants had positive expectations from participating in a weight loss program. Therefore, the above list includes some of them and it cannot be exhaustive.

8. What are the challenges you are facing?

This question was phrased to elicit data on the challenges the overweight people faced while attempting to lose weight. These expressed challenges were believed to reflect the types of motivation they had towards losing weight. 


\section{Long Distance}

The discussants said that they were facing the challenges of the long distance between their home and the fitness centers they got support. Look the following excerpt:

For me, I've changed my living area which is far away from the center where my coach is working. The long distance prohibited me from getting regular support from my coach. I'm sad for this.

The interventionists also agreed with the challenges of long distance. Following the government's construction and distribution of condominium to the people, many of our clients changed their living areas and this caused them to travel long distances.

It is well documented that when facilities are far from one's permanent address, getting the service regularly will not be easy.

Friends and family members comment on my physical appearance. This sometimes makes me emotional which might interfere on my diet selection and the will to intensify the exercise.

Here I have made friends. We encourage one another. When I am forced to shift to other sessions,

I miss them and their encouraging words. This discomforts me.

The contribution of the people around the overweight person on the motivation of him/her to lose weight cannot be ignored. In these excerpts, the discussants revealed their discomforts which stemmed from the discouraging comments forwarded from friends. When the people around us are encouraging to our efforts, it is more likely that we make significant positive changes through losing weight.

\section{Amount of physical exercises}

The amount of physical exercises they were required to do was among the challenges the discussants mentioned during their discussion.

Depth of physical exercises. I mean length of time for physical exercise

Apovian (2016) reported that overweight people need to engage in physical activity with moderate intensity appropriate to the overweight person. The level might be challenging if the interventionist does not handle it professionally or if the overweight person is not well motivated to involve in physical exercise. Both are manageable, however.

\section{Selecting Dietary}

The other challenge emanated from the struggle to be in line with the dietary schedule suggested from fitness centers the overweight people received support.

\section{Being off schedule of the some food items which I enjoy eating}

When food items I don't like eating are included in the schedule An individual's dietary choices could be impacted by past experiences with food selection. If those habits are unhealthy, bringing behavioral change in dietary selection could be a major challenge (Beck, 2015). There will be a temptation to be attracted to the previous likes of food items.

\section{On Behavioral and Financial Challenges}

The discussants mentioned the following challenges. These challenges could be summarized as behavioral and financial. The excerpts presented next reveal these challenges.

Unable to be punctual, except this I have no other problem.

\section{On being on time}

These days life is difficult. The price of everything, including daily consumptions, is soaring. This may cause financial burden to the level of failing to settle fee for the center.

We heard that some dropped from the intervention due to shortage of money to pay for the center. If they had shared us, we would have had different paying modalities which can accommodate them.

9. Did you quit from participating in weight loss program? Do you know people who did so? What were the reasons?

This question was aimed at gleaning information about if they dropped from participating in a weight loss program. Their responses revealed the type of motivation they held to stop or to continue with the intervention. These 
responses were believed to contribute to the content validity of the indicators to be generated. Shortage of time

These days life is difficult. The price of everything, including daily consumptions, is soaring. This may cause financial burden to the level of failing to settle fee for the center. I know someone who quitted for this reason. I have friends er...er... who er...er...er...withdrew from going to...to fitness centers
er...because ....er...er... they don't see changes on their physical appearance.

\section{Indicators in SDT}

The analysis under this subsection is to address the second research question which runs, "Where do the indicators fit in the factors of social determination theory (SDT)?" According to SDT, the indicators show the adherence to weight loss. Adherence to weight loss practices distributes along a continuum from intrinsic motivation to amotivation (Deci \& Ryan, 1985): Intrinsic motivation, extrinsic motivation, which includes integrated motivation, identified motivation, introjected motivation and external motivation, and amotivation. These types of motivations are briefly discussed one by one.

Someone is intrinsically motivated when he/she does something for the pleasure experienced in the process (Deci, 1975 in Lavesque and Vallerand, 2007). This refers to the type of behavioral regulation in which it is chosen freely. The reward is the behavior itself and it is something pleasant. For instance, an overweight man might decide to participate in an intervention because he wants to challenge himself and he really enjoys the process. According to Teixeira, Silva, Mata, Palmeira, and Markland (2012), research on SDT and weight control show that there is a positive association between autonomy (intrinsic motivation) and long term weight loss. This leads to a greater association of intrinsic motivation with the satisfaction of needs which in turn shapes the individual's adherence to weight loss practices.

Integrated motivation represents the most independent form of extrinsic motivation that happens when there is heterogeneity between behavior rules and needs, goals and personal confirmed values which are part of the person. For example, overweight people might participate in a weight loss program because participation is an integral part of their life.

Identified motivation refers to an individual thinking that the behavior is valuable, but it is done as it is considered to be an advantage for the subject. There might be overweight individuals who might follow this cause. Their behavior reflects conscious values and is internalized as personally important (Lavesque and Vallerand, 2007). For example, the overweight man might participate in weight loss programs to eventually reach his target of scoring the right BMI.

Introjected motivation refers to a person performing the behavior so as not to feel guilty or uneasy about not having exercised. Some overweight people might engage themselves in weight loss programs and reflect introjected regulation which represents a partial internalization without completely accepting it as one's own (Lavesque and Vallerand, 2007). An overweight man may begin to keep a journal of the food he consumes on a daily basis because the overweight people in his weight loss group do so. To give another example, students who go to a science class to avoid feeling of guilty.

External motivation refers to the way a person performs behaviors as a means of obtaining an external reward or due to influence by external subjects or factors. In other words, the behavior is controlled by external forces. Some obese people might be externally motivated to involve in the practice of weight loss. Their behavior to participate in such practices is for external rewards. For example, an overweight man may change his diet and add physical exercise as part of the intervention to weight loss in order to avoid criticism from physician.

Still there might be amotivated overweight people whose behavior is characterized by a relative lack of motivation (Lavesque and Vallerand, 2007). Amotivation covers a person's non intentional behavior. That is, there is no clear reason for an individual exercising. An overweight man might involve in weight loss program even though he does not see the benefit in what he is doing.

Sample excerpts and their corresponding categories are presented in the following table. 


\begin{tabular}{|c|c|c|}
\hline & Excerpts & Category \\
\hline 1 & I did it er...er ... for a long... a long time and it...it is almost part of mine ...er...my life & Integrated \\
\hline 2 & $\begin{array}{l}\text { It is ... almost a habit for me and I don't...er....er...feel good if I am not doing ....er I } \\
\text { am not doing physical exercise }\end{array}$ & Introjected \\
\hline 3 & $\begin{array}{l}\text { For me, I ... did it for more than er...er...er... yes for more than } 12 \text { years. When I } \\
\text { began, er... it was to...to..to improve my health status. I saw... I achieved this. I } \\
\text { continued involving in the weight loss program. It is almost...er almost part of of my } \\
\text { life....I don't know how life looks like without physical exercise and diet selection. }\end{array}$ & Integrated \\
\hline 4 & $\begin{array}{l}\text { Yea...for some it is almost a habit. Their body accustomed to the rules and } \\
\text { regulations of the weight loss program. They feel ashamed of themselves. .... They feel } \\
\text { guilty when they cancelled schedule. }\end{array}$ & Introjected \\
\hline 5 & ...for the joy I...er... feel when I engage to...to... myself in the weight loss procedure & Intrinsic \\
\hline 6 & I want others to admire me (laughing) & External \\
\hline 7 & ...to have a good relationship with others & Identified \\
\hline 8 & $\begin{array}{l}\text { Er...for me...the joy of doing/involving in the weight loss ... In fact, er...er... the } \\
\text { weight loss is a secondary reason-my primary reason is er...er...er... the pleasure I } \\
\text { get...get from coming here. }\end{array}$ & Intrinsic \\
\hline 9 & $\begin{array}{l}\text { Like Selam said, People will admire me, I hope, ...because it is a big success } \\
\text { er...er...imagine if I throw this (touching and squeezing her belly) way. }\end{array}$ & External \\
\hline 10 & $\begin{array}{l}\text { I know a young boy who goes to a fitness center for no reason. So he sometimes } \\
\text { comes sometimes does not....Teddy, added in a humorous tone There are many } \\
\text { especially the teenagers.(others laugh) }\end{array}$ & Amotivation \\
\hline 11 & $\begin{array}{l}\text { In fact, we have clients who come... I mean ...er...er appear to the center, but er...they } \\
\text { don't follow the schedules. This er...er... we tell them again and again...this won't } \\
\text { bring the desired result. We don 't... encourage...such behaviors. }\end{array}$ & Amotivation \\
\hline 12 & $\begin{array}{l}\text { To have a good relationship with my friends who are working in the entertainment } \\
\text { industry. }\end{array}$ & Identified \\
\hline 13 & $\begin{array}{l}\text {...if...er...even ...even though it is hard to select and leave some of the foods... I liked } \\
\text { before..hahaha I don't eat such food because such hard decisions improve my weight } \\
\text { loss performance. }\end{array}$ & Identified \\
\hline 14 & I like...I enjoy...I mean I must do physical exercises periodically. & Introjected \\
\hline 15 & I have a friend who said dieting is an integrated part of her life & Integrated \\
\hline 16 & $\begin{array}{l}\text { I want show ...her...I want my wife...er...I am good at exercising which help me } \\
\text { manage my weight }\end{array}$ & External \\
\hline 17 & $\begin{array}{l}\text { I eat unhealthy food... because er...er... I don't ... want my family and friends be } \\
\text { unhappy }\end{array}$ & External \\
\hline 18 & $\begin{array}{l}\text { Well...in my side...er...er...to talk truth I will be embarrassed if I failed off scheduled } \\
\text { of the center }\end{array}$ & Introjected \\
\hline 19 & $\begin{array}{l}\text {...my friend I ...my friend takes the responsibility for his overweight... he blames } \\
\text { nothing... he...yes enjoys the program }\end{array}$ & Intrinsic \\
\hline 20 & My first goal is ... well...no other only the right BMI & Identified \\
\hline 21 & Prioritizing my health is the principle of my life. & Integrated \\
\hline
\end{tabular}

\section{Limitations and Further Research}

The current study used BMI to recruit overweight people. However, this index is known to fail to distinguish between fat and fat-free mass. Besides, waist circumference was not employed to select overweight people. Future researchers can consider these criteria to recruit their participants.

The current research did not consider excess body weight affected by genetic factors, health conditions, and drug use. These could also be target areas for future research.

\section{Conclusion}

We showed that it is possible to use qualitative research, more specifically FGDs, to generate possible indicators for a construct of motivation for participating in a weight loss program. Scientific procedures were employed to make these indicators represent the real life domain of the target respondents' reason to involve in a weight loss program. Besides, these indicators were coded against the types of motivations explained under social determination theory (SDT). 
Acknowledgment

The authors would like to thank the study participants for their willingness. We are grateful to thank fitness center administration and interventionists for helping with the sampling and recruitment procedures.

\section{Ethics Approval}

As with any aspect of formal data collection procedure protection of participants from conveniences is very important. This called for the oversight by the institutional review board of Hawassa University. Therefore, ethical clearance was secured from College of Education in the aforementioned University. Permission was also requested and obtained from authorities of the research site. Besides, focus group discussion members were made to know the focus of the questions being forwarded to them, were informed of any identified risks, and were given the opportunity to give their verbal consent. The consent wouldn't deny them their exit from the discussion at any stage of the research. In order to keep confidentiality of any information provided by study participants, the data collection procedure was made anonymous.

\section{Declaration of Conflicting Interests}

The author(s) declared no potential conflicts of interest with respect to the research, authorship, and/or publication of this article.

\section{References}

Andres, A., Saldana, C., and Beeken, J.R. (2015).Assessment of Processes of Change for Weight Management in UK Sample.Obesity Facts.The European Journal of Obesity. 8, 43-53.

Apovian, M. C. (2016). Obesity: Definition, Comorbidities, Causes, and Burden. The American Journal of Managed Care. 22/7, 176-185.

Beck, B.A. (2015). A Small Change Approach to Weight Loss in Obese Adult Patients: A Research Translation Project. Unpublished Doctor of Nursing Practice (DNP). Project-57.

Berg, L. B. (2001). Qualitative Research Methods for the Social Sciences (4 ${ }^{\text {th }}$ Ed.) Boston: A Pearson Education Company.

Ceccarin, M. (2015). From Food Addiction to Motivation in Weight Management: new perspectives in the treatment of obesity. Unpublished PhD Dissertation. University of Bergamo.

Cox, E.C. (2017).Role of Physical Activity for Weight Loss and weight Maintenance.Spectrtum.Diabetes Journal.Org. 30/3, 157-160.

Crane, M.M., Fate, F.D., Finkelstein, A.E. and Linnon, A. L. (2012). Motivation for Participating in a Weight Loss Program and Financial Incentives: Analysis from a Randomized Trial. Journal of Obesity. Article ID 290589, 9 pages.

Creswell, W. J. (2012). Educational Research: Planning, Conducting, and Evaluating Quantitative and Qualitative Research (4 ${ }^{\text {th }} \mathrm{ed}$.). Boston: Pearson Education Inc.

Dagim, A. and Minyahil, T.B. (2017).Determinants of Obesity among Working Adults in WolaitaSodo Town, Southern Ethiopia.International Journal of African and Asian Studies.39, 14-21.

Deci, E. L., Ryan, R. M. (1985) Intrinsic Motivation and Self-determination in Human Behavior. Plenum, New York, NY

Dereje Y. T., Gudina E. A. and Tefera C. M. (2018). Overweight and Undernutrition in the Cases of School-Going Adolescents in WolaitaSodo Town, Southern Ethiopia: Cross-Sectional Study. Journal of Nutrition and Metabolism. http://doi.org/10.1155/2018/8678561.

Desalegn D. (2016).Assessment of Sleep Duration and Overweight/Obesity among High School Adolescents in Addis Abaaba, Ethiopia. A Thesis Submitted to the School of Graduate Studies of Addis Ababa University, College of Health Sciences, School of Health in Partial Fulfillment of the Requirements for the Degree of Master in Public Health. Addis Ababa University: Unpublished.

Ethiopian Public Health Association (2012).Emerging Public Health Problems in Ethiopia: Chronic NonCommunicable Diseases.

Gurevich-Panigrahi, T., Panigrahi, S., Wiechec, E. and Los, M. (2009). Obesity: Pathophysiology and Clinical Management. Current Medicinal Chemistry. 16/1, 506-521.

Kelly T, Yang W, Chen C, Reynolds K, He J. (2008) Global burden of obesity in 2005 and projections to 2030. Int J Obes. 32 (9):1431-1437. [doi: 10.1038/ijo.2008.102]

Lavesque, L. G. and Vallerand, J. R. (2007). A Motivational Model of Persistence in Science Education: A SelfDetermination Theory Approach. European Journal of Psychology of Education.22/3, 351-369.

Miles, M. B. and Huberman, M. (1994). Qualitative Data Analysis. (2 ${ }^{\text {nd }}$ Ed.). Thousand Oaks, CA: Sage Publication.

Mulugeta, S., Mekitie W, Alemayehu A, Shikur M, ZewduSh, Mukerem A, Gebresilasea G. (2015) Magnitude and Determinants of Overweight and Obesity among High School Adolescents in Addis Ababa, Ethiopia. 
Journal of Food and Nutrition Sciences. 3(5): 166-173.

NHLBI Obesity Education Initiative (2000). The Practical Guide: Identification, Evaluation, and Treatment of Overweight and Obesity in Adults. North America: NIH Publication Number 00-4084.

Ogunbode, A., Ladipo, M., Ajayi, I. and Fatiregun, A. (2011). Obesity: An Emerging Disease. Nigerian Journal of Clinical Practice. 14/4, 390-394.

Patton, Q. M. (2015). Qualitative Research Evaluation Methods. ( $4^{\text {th }}$ Ed.) Los Angeles: SAGE Publications, Inc.

Sand, A., Emaus, N. and Lian, S. O. (2017). Motivation and Obstacles for Weight Management among Young Women - a Qualitative Study with a public health focus - the Tromsø Study: Fit Futures. BMC Public Health. 17: 417, 1-11.

Solomon A., Solomon, S., and Kedir, Y. (2016). Overweight and Obesity and its Socio-demographic correlates among Urban Ethiopian Women: Evidence from the 2011 EDHS. BMC Public Health.Doi 10.1186/s12889016-3315-3.

Teixeira, P. J., Silva, M. N., Mata, J., Palmeira, A. L., \& Markland D. (2012). Motivation, self-determination, and long-term weight control. International Journal of BehavioralNutrition and Physical Activity, 9, 1-13. doi: 10.1186/1479-5868-9-22

Tennant, M. (2014).Exploring Media Representations of Overweight and Obesity Women's Dietary and Exercise Behaviors in The Biggest Loser: A Self-Determination Approach. A Thesis Submitted in Partial Fulfillment of the Requirements of the Degree of Master of Arts Interdisciplinary Health. Ontario: Laurentian University: Unpublished.

Tesfalem T., Singh, P. and Debebe M. (2013) Prevalence and Associated Factors of Overweight and Obesity Among High School Adolescents in Urban Communities of Hawassa, Southern Ethiopia.Current Research in Nutrition and Food Science. Vol. 1(1), 23-36.

Tesfalem, T., Singh, P., Moges, D., (2013) Prevalence and associated factors of overweight and obesity among high school adolescents in urban communities of Hawassa, Southern Ethiopia, Current Research Nutrition Food Science Journal, 1(1), 23 - 36.

Wilkinosn, D. and Birmingham, P. (2003). Using Research Instruments: A Guide for Researchers. London: Routledge Falmer.

Yatsuya, H., Li, Y., Hilawe, H. E., Ota, A., Wang, C. Chiang, C., Zhang, Y., Uemura, M., Osako, A., Ozaki, Y. and Aoyama, A. (2014). Global Trend in Overweight and Obesity and Its Association with Cardiovascular Disease Incidence.Circulation Journal. 78, 2807-2818. 